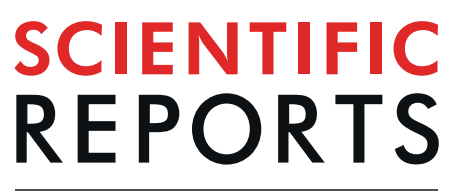

natureresearch

\title{
OPEN Author Correction: Rice plants overexpressing OsEPF1 show reduced stomatal density and increased root cortical aerenchyma formation
}

\author{
U. Mohammed ${ }^{1}$, R. S. Caine $\mathbb{1}^{2}$, J. A. Atkinson ${ }^{1}$, E. L. Harrison ${ }^{2}$, D. Wells ${ }^{1}$, C. C. Chater ${ }^{2}$, \\ J. E. Gray $\mathbb{D}^{2}$, R. Swarup ${ }^{1}$ \& E. H. Murchie ${ }^{1}$
}

Correction to: Scientific Reports https://doi.org/10.1038/s41598-019-41922-7, published online 03 April 2019

The Acknowledgements section in this Article is incomplete.

“This work was supported by the Biotechnology and Biological Sciences Research Council [grant numbers BB/ R004633/1, BB/N021061/1, BB/N013646/1]. JAA and DMW receive funding from the University of Nottingham Future Food Beacon of Excellence. We thank Dr Amanda Rasmussen (University of Nottingham) for assistance with the oxygen sensor."

should read:

"This work was supported by the Biotechnology and Biological Sciences Research Council [grant numbers BB/R004633/1, BB/N021061/1, BB/N013646/1 and BB/P010520/1]. JAA and DMW receive funding from the University of Nottingham Future Food Beacon of Excellence. We thank Dr Amanda Rasmussen (University of Nottingham) for assistance with the oxygen sensor."

(i) Open Access This article is licensed under a Creative Commons Attribution 4.0 International Cicense, which permits use, sharing, adaptation, distribution and reproduction in any medium or format, as long as you give appropriate credit to the original author(s) and the source, provide a link to the Creative Commons license, and indicate if changes were made. The images or other third party material in this article are included in the article's Creative Commons license, unless indicated otherwise in a credit line to the material. If material is not included in the article's Creative Commons license and your intended use is not permitted by statutory regulation or exceeds the permitted use, you will need to obtain permission directly from the copyright holder. To view a copy of this license, visit http://creativecommons.org/licenses/by/4.0/.

(C) The Author(s) 2019

${ }^{1}$ Division of Plant and Crop Science, School of Biosciences, University of Nottingham, Sutton Bonington campus, LE12 5RD, Nottingham, UK. ${ }^{2}$ Department of Molecular Biology and Biotechnology, University of Sheffield, Western Bank, S10 2TN, Sheffield, UK. Correspondence and requests for materials should be addressed to E.H.M. (email: erik. murchie@nottingham.ac.uk) 